\title{
Assessment of Farmers' Benefits Derived from Olam Organisation's Sustainable Cocoa Production Extension Activities in Ondo State, Nigeria
}

\author{
Akinnagbe O.M*. and Ajayi A.R. \\ Department of Agricultural Extension, \\ University of Nigeria, Nsukka, Enugu State, Nigeria \\ *E-mail: wolexakins@yahoo.com; Mobile: +2348035399151
}

\begin{abstract}
The study assessed farmers' benefits derived from Olam organization's sustainable cocoa production extension activities in Ondo state. Structured and validated interview schedule was used to collect relevant information from thirty cocoa farmers, using multistage random sampling technique from cocoa producing towns (Aponmu, Irese, Laagba, Bagbe, Oboto, Igbo-Ore, Igodo, Arogbo, Ago paanu and Agogo) used by Olam in the state. Data were analyzed using percentage, mean and correlation statistics. The findings revealed that cocoa farmers had benefited from the Olam's extension activities in terms of improved knowledge and skill acquisition in cocoa production as well as economic gains in terms of yield and income. The result of correlation shows that the number of years spent in school $(r=-0.389)$ and household size $(r=-0.437)$ had negative and significant relationship with benefits derived from Olam organization. It was recommended that effective monitoring and evaluation team should be established by Olam organization to improve on the good performance already recorded.
\end{abstract}

Keywords: Cocoa, benefits, Olam Organisation, Ondo State.

\section{Introduction}

Cocoa (Theobroma cacao) is one of the most important perennial crops worldwide. It remains, however, significant in terms of internal revenue generation, and at the grower level is important in terms of employment and income. Cocoa, a plantation crop, was the dominant foreign exchange earner from the early 1960s through the 1970s (Olujide and Adeogun, 2006). It also remains a major export crop; in 1998 a revenue of 7459.3 million Naira (US\$ 53,280 at 140 per US\$) was derived from dried cocoa beans (half of the income attributed to the total export of major agricultural products) (CBN, 1998). In quantitative terms, the contribution of the cocoa sub-sector to Nigeria's total agricultural export earnings averaged $70.6 \%$ between 1971 and 1975, 89.8\% between 1976 and 1980, 84.6\% between 1985 and 1987, 76.8\% between 1986 and 1990, and 53.3\% between 1992 and 1996 . Although these figures indicated a declining trend, the situation is a reflection of the less important roles, which the agricultural sector has assumed in export earnings, having been strongly dominated by oil exports in more recent years (Agboola, 2005).

The fall in percentage share of cocoa output may be attributable to two reasons as noted by Amos (2007). Firstly, the negligence of the agricultural sector by the past administrations due to the discovery of the petroleum resources that now account for the enormity of foreign exchange earnings; thus, neglecting cocoa. Secondly, the endemic problems in the cocoa industry have led to the dwindling nature of cocoa production. Among these are the vacuum created by the abolition of the Nigerian Cocoa Marketing Board (NCMB), old age of the farmers, massive migration from rural areas to urban areas, scarcity and high cost of agricultural labour, incidence of pests and diseases, lack of credit facilities to cocoa farmers and 
indiscriminate bush burning that has been affecting cocoa plantations (CDU, 2003; CRIN, 2003).

To resuscitate cocoa production and marketing; and hence, salvage the cocoa industry from further declining, some individuals and private organizations have been seriously involved in the resuscitation processes to complement the efforts of the various governments. Among these private organizations is the Olam Nigeria Ltd. Olam, a private, commercial and multi-product company was established by the Kewalram Chanrai Group (KCG), with its headquarters in Singapore and principal office in Lagos, Its regional offices are found in Kano and Akure. It provides what could be called specialized extension services and uses specific agricultural products (such as cocoa, coffee, cashew, sheanuts, sesame, rice and teak wood) as industrial materials. Its cocoa business began in Nigeria in 1992 and has participated in all aspects of cocoa business like production, marketing and processing, in the cocoa-producing states such as Ondo, Osun, Ekiti, Edo, Ogun, Cross River, Taraba and Adamawa (Olam, 2007).

Having been involved in cocoa business for years, one would like to find out the various extension activities embarked upon by this organization in resuscitating cocoa industry. Of what benefits are these organization's activities to the cocoa farmers in Ondo state? The study was also designed to determine whether or not relationship exist between cocoa farmers' personal characteristics and benefits derived from Olam organization.

\section{Objectives of the study}

The general objective of the study was to assess the benefits derived from Olam organization's sustainable cocoa production extension activities by farmers in Ondo state.

Specifically, the study was designed to:

(i) describe the socio-economic characteristics of cocoa farmers in the study area;

(ii) determine the benefits derived from Olam organization's sustainable cocoa production extension activities by farmers in Ondo state; and

(iii) ascertain relationship between personal characteristics of the cocoa farmers and benefits derived from Olam organization.

\section{Methodology}

The study was carried out in Ondo State. The state is located in the southwestern part of the country. It lies between latitudes $5^{\circ} 45^{1}$ and $7^{\circ} 52^{1}$ North of the equator and longitudes $4^{\circ} 20^{1}$ and $6^{\circ} 5^{1}$ East of Greenwich Meridian. Its land area is about 13,595 square kilometers. The climate of the area is highly favourable for the agrarian activities of her teeming population of 3,441,024 persons (NPC, 2007). Multistage random sampling technique was employed in the selection of the respondents (farmers) for this study. Firstly, Ondo state was purposively selected out of the three states (Ondo, Osun and Ekiti) used by Olam organization as model states in Southwestern state because of its highest number of model farmers among other states. The second stage involved random selection of 10 cocoa producing communities (Aponmu, Irese, Laagba, Bagbe, Oboto, Igbo-Ore, Igodo, Arogbo, Ago paanu and Agogo) from the list of 70 communities used by Olam organization in Ondo state. 
A list of Olam's model farmers (participating cocoa farmers) was obtained from the management of Olam organisation. From the list, 3 farmers each were selected through simple random sampling technique, from the 10 selected communities, making a total of 30 Olam farmers (OFs). Data for the study were collected from the respondents through the use of structured interview schedule. Content and face validity were carried out to ensure that the instrument collect the data it is meant to collect. This was done by lecturers in the Department of Agricultural Extension, University of Nigeria, Nsukka before field administration.

Information on the socio-economic characteristics of the respondents were examined. Respondents were asked to indicate their age (years), sex, educational level, religion, household size age of their cocoa plantation (years) and farming experience (years). Other variables measured include involvement in social organization, the management system adopted and their sources of finance. Respondents were also asked to indicate the various extension activities engaged by Olam organization in improving cocoa business.

To determine the perceived level of benefits of cocoa improvement extension activities to farmers, a list of variables / possible benefits (e.g. Increase in productivity, increased income, higher yield, etc), was given on a 5 -point Likert-type scale with five response options ( $5=$ to a great extent; $4=$ to some extent; $3=$ to a little extent; 2 = to a very little extent; $1=$ No extent). The values on the Likert-type scale were added to obtain 15 , which was later divided by 5 , to obtain a mean score of 3.0. Then, any mean score that was equal or higher than 3 was perceived as a benefit derived from the organization cocoa programmes while a mean score lower than 3.0 was perceived as not a benefit. Data were analyzed using percentages, mean statistics and spearman's (rho) correlation coefficient.

\section{Results and Discussion \\ Socio-economic characteristics of cocoa farmers}

Data in Table 1 revealed that $33.3 \%$ of the Olam cocoa farmers were within the age range of $51-60$ years old, while $23.3 \%$ of them were between 61 and 70 years of age. Those that fell within 31-40 years, 41-50 years and 71-80 years accounted for $10.0 \%, 16.7 \%$ and $16.7 \%$, respectively. Their mean age was 58 years. Thus, the farmers are old and should be able to make rational decision with respect to cocoa production activities. This finding corroborates the expression of Amos (2007) that an average cocoa farmer in Ondo State is old.

Majority $(90.0 \%)$ of the Olam cocoa farmers in Ondo state were males while $10.0 \%$ of them were females. This implies that men predominate in cocoa production than the female farmers, though the female farmers have their own roles to play, especially, in the maintenance and processing of cocoa beans as indicated by Adetunji, Olaniyi and Raufu (2007). About $47 \%$ of the respondents completed primary education, $23.3 \%$ attempted primary schools and tertiary education respectively. Only $6.7 \%$ completed secondary school education. It could be inferred that, cocoa farmers in the study area are literates who could read and write. This could serve as an impetus in adopting cocoa technologies. According to Obinne (1991), education is an important factor influencing adoption of farm innovations. Also, about $93 \%$ of the farmers were Christians, while about $7 \%$ were Muslims. This implies that Christianity predominate the study area.

Data in Table 1 further revealed that majority $(56.7 \%)$ of the Olam cocoa farmers had a household size of 1 to 5 people, while $33.3 \%$ of them had 6 to 10 
people, and the remaining $3.0 \%$ had between 11 and 15 people. The farmers had a mean household size of 6 people. This implies that the farmers had a fairly large household which could probably serve as an insurance against short falls in supply of farm labour. Household size has a great role to play in family labour provision in the agricultural sector (Sule, Ogunwale and Atala 2002).

About $10 \%$ of the Olam cocoa farmers had cocoa plantations that were of 1120 years and 21-30 years. Those that had their cocoa plantations between 31 and 40 years, 41 and 50 years and 51 and 60 years accounted for $30.0 \%, 13.3 \%$ and $16.7 \%$, respectively. Their mean cocoa plantation age was 36 years. The optimum economic life of cocoa plantation according to Oshikalu in Idowu et al (2007) is 30 years. The fact that the mean cocoa plantation age was about 36 years calls for meaningful renovation.

Entries in Table 1 revealed that a greater proportion (56.7\%) of the Olam farmers had farming experience of 31 to 40 years, while $10.0 \%$ and $13.3 \%$ of them had farming experience of 11 to 20 years and 21 to 30 years, respectively. Those that had between 41 and 50 years, and 51 and 60 years of farming experience accounted for $13.3 \%$ and $6.7 \%$, respectively. Their mean farming experience was about 37 years. These findings imply that the farmers had fairly long period of farming experience which could serve as an advantage for increased participation in cocoa resuscitation extension activities since this experience is important for day-today running of the farming activities, as cocoa cultivation is a very tasking business. 
Table 1: Distribution of respondents according to personal and socioeconomic characteristics

\begin{tabular}{|c|c|c|c|}
\hline Characteristics & Frequency & $\begin{array}{c}\text { Percentage } \\
(\%)\end{array}$ & $\bar{x}$ \\
\hline \multicolumn{4}{|l|}{ Age (years) } \\
\hline $31-40$ & 3 & 10.0 & \\
\hline $41-50$ & 5 & 16.7 & 58.0 \\
\hline $51-60$ & 10 & 33.3 & \\
\hline $61-70$ & 7 & 23.3 & \\
\hline $71-80$ & 5 & 16.7 & \\
\hline \multicolumn{4}{|l|}{ Sex } \\
\hline Male & 27 & 90.0 & \\
\hline Female & 3 & 10.0 & \\
\hline \multicolumn{4}{|l|}{ Education level } \\
\hline Primary school attempted & 7 & 23.3 & \\
\hline Primary school completed & 14 & 46.7 & \\
\hline Secondary school completed & 2 & 6.7 & \\
\hline Tertiary (OND,NCE, HND/first degree) & 7 & 23.3 & \\
\hline \multicolumn{4}{|l|}{ Religion } \\
\hline Christianity & 28 & 93.3 & \\
\hline Islam & 2 & 6.7 & \\
\hline \multicolumn{4}{|l|}{ Household size } \\
\hline $1-5$ & 17 & 56.7 & \\
\hline $6-10$ & 10 & 33.3 & 6 \\
\hline $11-15$ & 3 & 10.0 & \\
\hline \multicolumn{4}{|l|}{ Age of cocoa plantation (years) } \\
\hline $11-20$ & 3 & 10.0 & \\
\hline $21-30$ & 9 & 30.0 & \\
\hline $31-40$ & 9 & 30.0 & 36.1 \\
\hline $41-50$ & 4 & 13.3 & \\
\hline & 5 & 16.7 & \\
\hline \multicolumn{4}{|l|}{ Farming experience (years) } \\
\hline $11-20$ & 3 & 10.0 & \\
\hline $21-30$ & 4 & 13.3 & \\
\hline $31-40$ & 17 & 56.7 & 36.6 \\
\hline $41-50$ & 4 & 13.3 & \\
\hline $51-60$ & 2 & 6.7 & \\
\hline
\end{tabular}

\section{Involvement in social organization}

Fig. 1 shows that, majority $(50.0 \%)$ of the cocoa farmers belonged to farmers' groups, $20.0 \%$ belonged to cooperative societies, while about $10 \%$ belonged to political group. The remaining $20.0 \%$ were not involved in any social organization. These findings show that majority $(80.0 \%)$ of the respondents' belonged to different social organizations which is generally considered an important variable that enhances farmers' adoption of new practices as noted by Ekong (2003). This could influence the rate of adoption of cocoa innovations since they are more likely to be exposed to communication messages that are related to cocoa resuscitation activities more than their other counterparts due to group dynamic effects. 




Fig. 1: Involvement in social organisation

\section{Sources of finance}

Fig. 2 shows that, about $97 \%$ of the Olam's farmers financed their farm projects through personal savings. Only $3.3 \%$ of them got loan from a cooperative society to finance their cocoa farms. This implies that personal savings constitute the main source of fund for maintaining cocoa farm in the study area. This agrees with Nkang et al (2006) findings that access to bank loan by cocoa farmers is a big problem due to lack of collateral and the risky nature of agricultural production.

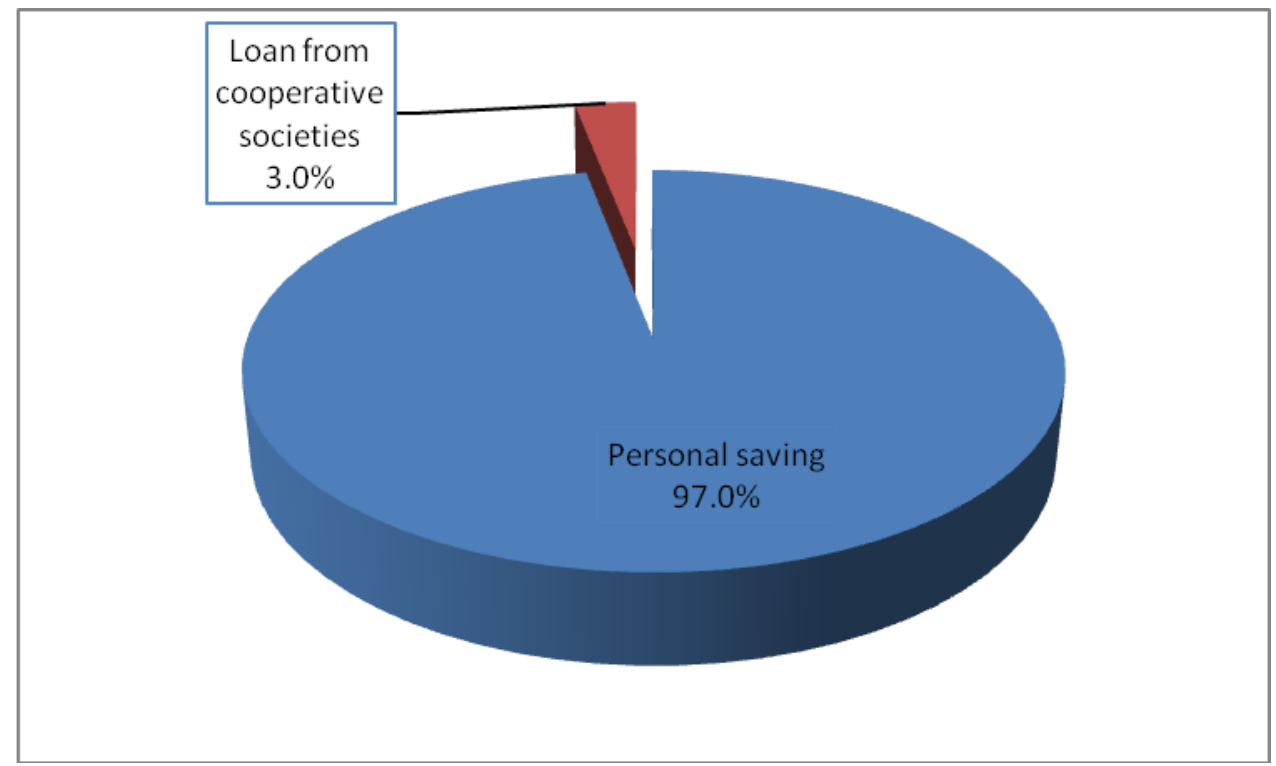

Fig. 2: Sources of finance 


\section{Management system adopted}

Fig. 3 shows that, majority $(60.0 \%)$ of the cocoa farmers adopted share-crop management system in their cocoa farms, while $36.7 \%$ of them adopted ownedmanagement system in their farms. Least management system was not common. This implies that sharecrop management system predominate among Olam farmers in the study area, hence this may lead to reduction in the profit accrued to the farmers since the revenue have to be shared between the owners.

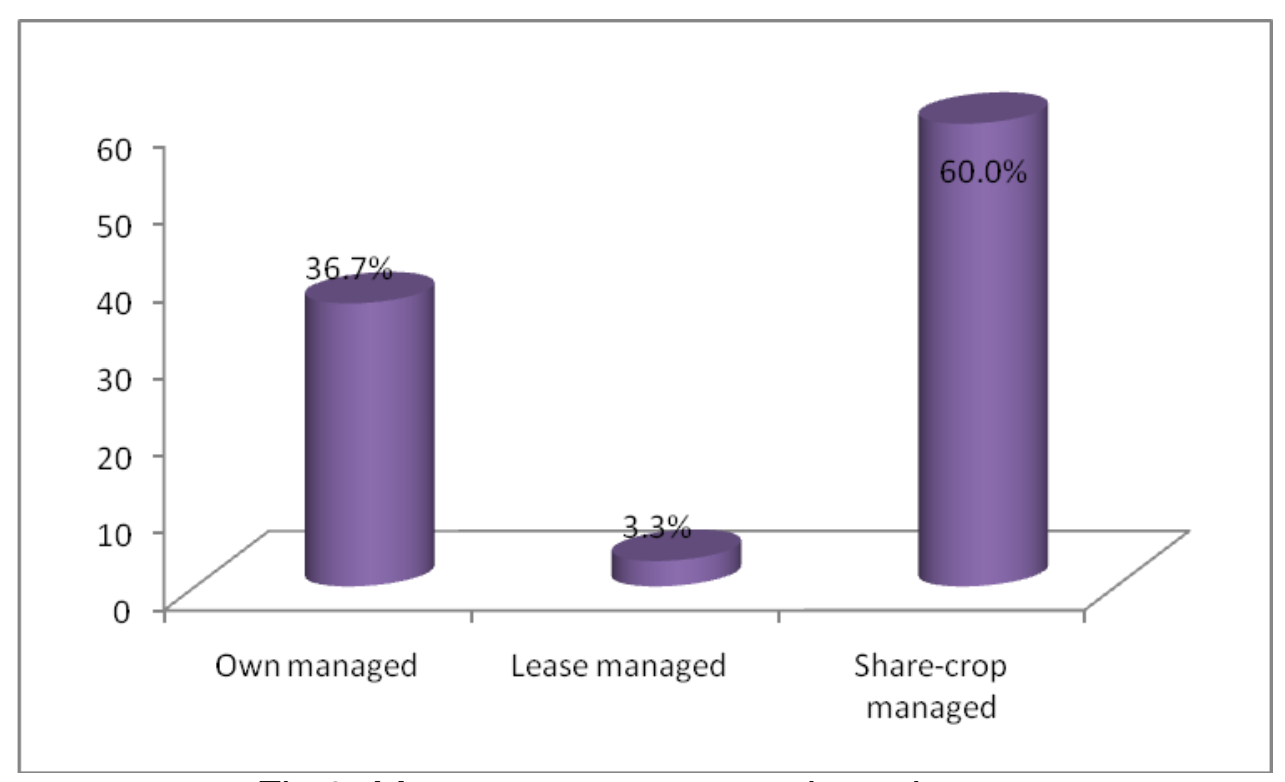

Fig.3: Management system adopted

\section{Olam Organization's Extension Activities}

Table 2 shows the distribution of respondents according to extension activities they were involved in. The table shows that Olam provided the following extension activities to their project cocoa farmers: supply of hybrid seedlings $(100.0 \%)$; visitation to cocoa farmers for adequate farm maintenance $(100.0 \%)$; distribution of agro-chemicals and other farm equipment (90.0\%); provision of technical advise to cocoa farmers on pre-planting, planting and post planting operations (90.0\%). Only about $43 \%$ of the cocoa farmers asserted that Olam rehabilitated old productive cocoa trees while none $(0.0 \%)$ of them attested that Olam granted loan at subsidized rate. This finding implies that, Olam's activities is majorly to encourage farmers to acquire inputs and be productive that will enhance good yield of cocoa. 
Table 2: Percentage distribution of the respondents according to Olam extension activities

\begin{tabular}{lc}
\hline Extension activities & $\%$ \\
\hline Rehabilitation of Old productive cocoa tree & 43.3 \\
Provision of hybrid seedlings & 100.0 \\
Distribution of Agro-Chemicals and other farm equipment & 90.0 \\
Training and awareness programme & 90.0 \\
Provision of technical advice to cocoa farmers on pre-planting, & 90.0 \\
planting and post planting operations & \\
Visitation to cocoa farmers for adequate farm maintenance & 100.0 \\
Granting of loan at subsidized rate & - \\
Marketing of cocoa and cocoa products & 3.3 \\
\hline
\end{tabular}

${ }^{*}$ Multiple responses

\section{Benefits Derived from Olam Organization's Extension Activities}

Table 3 shows the mean score of cocoa farmers according to the benefits derived from Olam extension activities. The major benefits derived includes: improved productivity $(\bar{x}=4.33)$, better quality of produce $(\bar{x}=4.30)$, better application of inputs $(\bar{x}=4.10)$ and improved knowledge of cocoa production $(\bar{x}=$ 4.40). This implies that, the knowledge gained during training and awareness programme of the ONLs, has led to better application of inputs, which invariably led to improved productivity.

Other benefits derived by OFs includes: increase in the level of annual income $(\bar{x}=3.90)$; positive change in attitude towards cocoa production $(\bar{x}=3.97)$; participation in formal organizations $(\bar{x}=3.53)$; ease of participation in agricultural and community development activities $(\bar{x}=3.33)$; increased level of social interaction $(\bar{x}=3.30)$; effective already made market for cocoa farmers $(\bar{x}=3.20)$; ease of paying children school fees $(\bar{x}=3.21)$; improvement in nutritional status $(\bar{x}=$ 3.13 ) and possession of household materials; beddings, furniture, cooking utensils $(\bar{x}=3.17)$. The implication of these findings is that, cocoa farmers in Ondo state have benefited from Olam's activities which reflected in terms of improved knowledge and skill acquisition in cocoa production as well as economic gains in terms of yield and income. 
Table 3: Mean Scores of respondents according to benefits derived from Olam organization

\begin{tabular}{lcc}
\hline Benefits & Mean $(\bar{x})$ & S.D \\
\hline Improved productivity & $4.33^{*}$ & 1.02 \\
Increased level of annual income & $3.90^{*}$ & 1.24 \\
Better quality of produce & $4.30^{*}$ & 0.91 \\
Better application of inputs & $4.10^{*}$ & 0.88 \\
Improved knowledge of cocoa production & $4.40^{*}$ & 1.02 \\
Increased level of social interaction & $3.30^{*}$ & 0.95 \\
Possession of household materials: Beddings, furniture, & $3.17^{*}$ & 1.00 \\
cooking utensils & & \\
Effective already-made market for cocoa farmers & $3.20^{*}$ & 1.44 \\
Improvement in Nutritional status & $3.13^{*}$ & 1.07 \\
Positive change in attitude towards cocoa production & $3.97^{*}$ & 1.12 \\
Participation in formal organization & $3.53^{*}$ & 1.19 \\
Ease of paying children school fees & $3.21^{*}$ & 1.29 \\
Ease of participation in agricultural and community & $3.33^{*}$ & 1.24 \\
development activities & & \\
\hline
\end{tabular}

* Derived benefit S.D = standard deviation

Relationship between personal characteristics of cocoa farmers and benefit derived from Olam organization

Table 4 shows the correlation analysis results between cocoa farmers' socioeconomic characteristics and benefits derived from Olam extension activities. The result of the correlation shows that number of years spent in school $(r=-0.389)$ and household size $(r=-0.437)$ had negative and significant relationship with benefits derived from Olam organization. This implies that, the longer the number of years spent in school, the less benefit derived from Olam extension activities. On the other hand, the higher the household size, the less benefit derived from Olam extension activities. From the result in Table 2, the major extension activity embarked upon by Olam organization are visitation for adequate farm maintenance and provision of hybrid seedlings to cocoa farmers. The tendency for highly educated person not benefiting much as compared to less educated person is high because of their educational background. They would have gotten some of this information required for adequate farm maintenance.

There is negative and non significant relationship between age $(r=-0.050)$, Age of cocoa plantation $(r=-0.170)$, farming experience $(r=-0.245)$, number of extension visit $(r=-0.244)$ and benefit derived from Olam extension activities, which indicates that the correlation of age, age of the cocoa plantation, farming experience and number of extension visit with benefit derived is not significant. 
Table 4: Result of correlation analysis between socio-economic characteristics of cocoa farmers and benefit derived from Olam organization

\begin{tabular}{ll}
\hline Variables & $\mathbf{r}$ \\
\hline Age & -0.050 \\
Age of cocoa plantation & -0.170 \\
Farming experience & -0.245 \\
Number of years spent in school & $-0.389^{*}$ \\
Household size & $-0.437^{*}$ \\
Number of extension visit & -0.244 \\
\hline${ }^{*}$ Significant $P \leq 0.05(2$-tailed) &
\end{tabular}

\section{Conclusion and Recommendation}

The study assessed the farmers' benefits derived from Olam organization's sustainable cocoa production extension activities in Ondo state The findings showed that majority of the cocoa farmers were male, married, Christian, had relatively large household sizes and long years of farming experience; and possessed at least first school leaving certificate. The findings further revealed that the respondents had benefited from the Olam's activities in terms of improved knowledge and skill acquisition in cocoa production as well as economic gains in terms of yield and income. The result of the correlation shows that number of years spent in school $(r=$ $-0.389)$ and household size $(r=-0.437)$ had negative and significant relationship with benefits derived from Olam organization. It was recommended that, effective monitoring and evaluation team should be established by Olam organization to improve on the good performance already recorded.

\section{References}

Adetunji, M.O., O.A. Olaniyi, and M.O. Raufu (2007). Assessment of Benefit derived by Cocoa farmers from Cocoa Development Unit Activities of Oyo State. Journal of Human Ecology. 22(3); 211-214.

Agboola, A.F. (2005). Socio-economic Assessment of Farmers' Usage of Indigenous and Non-Indigenous Pest Control Technologies in Cacao Agro-Ecosystems of Ondo and Osun States, Nigeria. Ph.D Thesis. Department of Agricultural Extension and Rural Sociology, Obafemi Awolowo University, Ile-Ife, Nigeria. Pp. $1-85$

Ajayi, A.R. (1996). An Evaluation of the Socio-Economic Impact of the Ondo State Ekiti-Akoko Agricultural Development Project on the Rural Farmers. Ph.D Thesis. Department of Agricultural Extension, University of Nigeria, Nsukka. Pp.1-290

Amos, T.T. (2007). An analysis of productivity and technical efficiency of smallholder cocoa farmers in Nigeria. Journal of Social Sciences. 15(2):127-133.

Central Bank of Nigeria (CBN), (1998). Annual report and statement of accounts for the year 1998. Central Bank of Nigeria. pp. 7-9.

Cocoa Development Unit (CDU) (2003). Information Booklet of Cocoa Development Unit Activities. Ibadan: CDU Publication. Pp.1-5.

Cocoa Research Institute of Nigeria (CRIN) (2003). Bulletin of Cocoa Research Institution of Nigeria (CRIN), Ibadan, Vol. 12.

Ekong, E.E. (2003). Rural Sociology, an Introduction and Analysis of Rural Nigeria. Uyo: Dove Educational Publishers. Pp. 256-288. 
International Cocoa Organisation (ICCO) (2003). ICCO Quarterly Bulletin of Cocoa statistics. Retrieved from http://www.icco.org

Idowu, E.O, Osuntogun D.A. and Oluwasola O (2007). Effects of Market Deregulation on Cocoa (Theobroma cacao) Production in Southwest Nigeria. African Journal of Agricultural Research. Vol. 2 (9). pp.429-434.

National Population Commission, (NPC) (2007). Population Figure. Federal Republic of Nigeria, Abuja. Retrieved from http://www.npc.gov

Nkang, N.M., Abang, S.O., Akpan, O.E. and Offem, K.J. (2006). Cointegration and error correction modelling of agricultural export trade in Nigeria: The case of cocoa. Journal of Agriculture and Social Sciences.

Obinne, C.P (1991). Adoption of improved cassava production technologies by small-scale farmers in Bendel State. Journal of Agricultural Science and Technology. 1(1): 12-15.

Olam (2007) Bulletin of Olam Nigeria Limited, Akure, Nigeria.

Olujide, M.G and S.O. Adeogun (2006). Assessment of cocoa growers' farm management practices in Ondo State, Nigeria. Spanish Journal of Agricultural Research, 4(2), pp.173-179.

Sule, A.M., Ogunwale, S.A. and Atala, T.K. (2002). Factors affecting adoption of fishing innovation among fishing entrepreneurs in Jebba Lake Community. In: T.A. Olowu (ed.), Journal of Agricultural Extension. Vol.6: 48-60. 